\title{
Potensi Produksi Asap Cair, Arang dan Ter dari Limbah Industri Pengolahan Kayu
}

\section{The Potential for Liquid Smoke, Charcoal, and Tar Production from Waste of The Wood Processing Industry}

\section{Alaik Z. H. Albaki ${ }^{1}$, Ahmad S. Purnama ${ }^{1}$, Fajri Yulianto ${ }^{1}$, Budy Rahmat ${ }^{1}$, Vita Meylani ${ }^{2, *}$}

\author{
${ }^{1}$ Jurusan Agroteknologi, Fakultas Pertanian, Universitas Siliwangi, Jl. Siliwangi No. 24, Tasikmalaya, Jawa \\ Barat 46115, Indonesia \\ ${ }^{2}$ Jurusan Pendidikan Biologi, Fakultas Keguruan dan Ilmu Pendidikan, Universitas Siliwangi, \\ Jl. Siliwangi No. 24, Tasikmalaya, Jawa Barat 46115, Indonesia \\ *Penulis korespondensi: Vita Meylani, e-mail: vibriovita@unsil.ac.id
}

Tanggal submisi: 2 Juli 2021; Tanggal penerimaan: 31 Agustus 2021; Tanggal publikasi: 9 September 2021

\begin{abstract}
The practice of burning and stockpiling to reduce wood waste from the wood processing industry is not in line with the demands of clean production, environmentally friendly and sustainable industries. Pyrolysis technology can be used to produce bioenergy from wood waste. The temperature and the time of the pyrolysis process, the water content of materials, and the content of different yields between types of wood waste affect the bioenergy products produced. This study was aimed at determining the effect of wood waste form and condition on the quality and quantity of liquid smoke, tar, and charcoal. A Completely Randomized Design with two factors of treatments, i.e., waste forms and the drying process, was applied in this research. The results showed that the condition and shape of the material affect the volume of liquid smoke and the weight of the charcoal produced. The condition of the material without drying with high water content and the shape of the chunks produce more liquid smoke with an average yield of $191.14 \mathrm{~mL}$ and $186.37 \mathrm{~mL}$, while the charcoal produced is higher in the condition of the material with drying and shaved form at $125.83 \mathrm{~g}$ and $115.62 \mathrm{~g}$. The results of the test characteristics of grade 1 and 2 distillation liquid smoke meet the Japanese liquid smoke quality standards with phenol levels in the range of 26.66-35.94 $\mathrm{mg}$ GAE/mL sample and acidity levels of 16.91-58.9\%.
\end{abstract}

Keywords: Char; liquid smoke; pyrolysis; tar; wood waste.

(c) The Authors. Publisher Universitas Pattimura. Open access under CC-BY-SA license.

\begin{abstract}
ABSTRAK
Praktik pembakaran dan penimbunan untuk mereduksi limbah kayu dari industri pengolahan kayu tidak selaras dengan tuntutan produksi bersih, ramah lingkungan dan industri berkelanjutan. Teknologi pirolisis dapat digunakan untuk memproduksi bioenergi dari limbah kayu dengan suhu dan waktu proses pirolisis, kadar air bahan serta kandungan rendemen yang berbeda antar jenis limbah kayu mempengaruhi produk bioenergi yang dihasilkan. Penelitian ini bertujuan untuk mengetahui pengaruh bentuk dan kondisi limbah kayu terhadap kualitas dan kuantitas asap cair, ter dan arang. Metode penelitian yang dilakukan adalah Rancangan Acak Lengkap yang disusun secara faktorial dengan perlakuan bentuk limbah dan proses pengeringan. Hasil penelitian menunjukan bahwa kondisi dan bentuk bahan mempengaruhi volume asap cair dan bobot arang yang dihasilkan. Kondisi bahan tanpa pengeringan dengan kadar air tinggi dan bentuk bongkah menghasilkan asap cair lebih banyak dengan hasil rata-rata 191,14 mL dan 186,37 mL, sedangkan arang yang dihasilkan lebih tinggi pada kondisi bahan dengan pengeringan dan bentuk serut yaitu 125,83 g dan 115,62 g. Hasil uji karakteristik asap cair distilasi grade 1 dan 2 memenuhi standar mutu asap cair Jepang dengan kadar fenol berada pada kisaran 26,66-35,94 mg GAE/mL sampel dan kadar keasaman 16,91-58,9\%.
\end{abstract}

Kata kunci: Arang; asap cair; limbah kayu; pirolisis; ter.

C Penulis. Penerbit Universitas Pattimura. Akses terbuka dengan lisensi CC-BY-SA. 


\section{PENDAHULUAN}

Limbah yang berasal dari pengolahan hasil pertanian dan kehutanan pada umumnya belum tertangani secara baik. Contoh yang banyak ditemui di Kota Tasikmalaya, limbah kayu dari industri rumahan (pengrajin) mebel hanya menumpuk di tempat pembuangan sampah dan bila tidak sempat dibakar akan terangkut truk sampah kota dan ditimbun di tempat pembuangan akhir. Menurut Purwanto (2011), limbah kayu dari industri penggergajian terdiri dari: sebetan kayu, potongan kayu dan serbuk kayu masing-masing sebesar 22\%, $8 \%$, dan $10 \%$ dari volume kayu batangan. Angkaangka tersebut belum termasuk volume limbah yang dihasilkan pada taraf pembentukan akhir seperti mebel, yakni serutan, serbuk dan potongan kayu.

Praktik pembakaran dan penimbunan untuk mereduksi limbah kayu (lignoselulosa) tidak selaras dengan tuntutan produksi bersih, ramah lingkungan dan industri berkelanjutan. Pembakaran limbah lignoselulosa berdampak meningkatnya emisi gas $\mathrm{CO}_{2}$ yang berkontribusi terhadap pemanasan global. Demikian pula, penimbunan limbah kayu di permukaan atau dalam tanah akan terjadi proses dekomposisi anaerob yang menghasilkan gas metana $\left(\mathrm{CH}_{4}\right)$, yang secara kualitatif memiliki dampak lebih kuat terhadap pemanasan global dibanding gas $\mathrm{CO}_{2}$ (Tiilikkala et al., 2010).

Di sisi lain dengan teknologi konversi, semua lignoselulosa segar (virgin biomass) dan lignoselulosa limbah (waste biomass) memiliki prospek dalam penyediaan bahan baku untuk memproduksi: i) biomaterial (makanan, pakan, pupuk, serat, biosida, bahan kimia, hasil kehutanan dll.); dan ii) bioenergi (arang, bioetanol, biogas) (Yokoyama dan Matsumura, 2008). Sehingga limbah tersebut memiliki potensi baik untuk dikembangkan yang nantinya dapat dimanfaatkan warga sebagai sumber pendapatan.

Teknologi pirolisis dapat digunakan untuk memproduksi bioenergi dari limbah kayu. Suhu dan waktu proses pirolisis, kadar air bahan serta kandungan rendemen yang berbeda antar jenis limbah kayu mempengaruhi produk bioenergi yang dihasilkan (Rahmat et al., 2014). Penentuan suhu dan waktu pirolisis yang tepat mengoptimalkan terjadinya pembentukan produk sehingga tidak ada zat sisa dari reaksi. Kadar air berpengaruh pada laju pembakaran serbuk gergaji menjadi arang. Kadar air rendah cenderung lebih mudah dan cepat terbakar daripada serbuk gergaji dengan kadar air yang tinggi (Nurhayati et al., 2006). Hal ini akan mempengaruhi suhu optimal penguraian limbah kayu dan waktu yang dibutuhkan akan semakin panjang jika bahan memiliki kadar air yang tinggi. Penelitian ini bertujuan untuk mengetahui pengaruh bentuk dan kondisi limbah kayu terhadap kualitas dan kuantitas asap cair, ter dan arang.

\section{METODE PENELITIAN}

\section{Bahan}

Bahan yang dipersiapkan untuk percobaan ini adalah limbah kayu sebagai sumber lignoselulosa yang dari industri penggergajian kayu dan pengrajin mebel.

\section{Pengambilan dan Persiapan Sampel Limbah Kayu}

Sampel limbah diambil dari industri pengrajin mebel, kelom geulis (sandal khas Kota Tasikmalaya yang berbahan dasar kayu), dan furniture berbahan dasar kayu yang berada di Kecamatan Tamansari dan Cibeureum Kota Tasikmalaya. Sampel diambil dari empat tempat yang berbeda dari masing-masing industri dan dilakukan metode pencampuran bahan sesuai dengan bentuknya, yaitu serbuk, bongkahan dan serutan. Jenis kayu yang digunakan merupakan kayu campuran dengan proporsi terbesar jenis Tisuk (Hibiscus macrophyllus) sebanyak $85 \%$ dan $15 \%$ lainnya dari campuran beberapa jenis tanaman berkayu seperti Albasia (Albizia falcataria), Bayur (Pterospermum javanicum), Mahoni (Swetenia mahagoni) dan Jati (Tectona grandis). Bahan yang telah diambil sesuai dengan bentuknya dibagi menjadi dua perlakuan, yaitu tanpa pengeringan (bahan segar) dan dengan pengeringan. Pengeringan dilakukan dibawah sinar matahari selama 16 jam sehingga menghasilkan kadar air bahan $\leq 15 \%$. Kadar air dihitung dengan menggunakan wood moisture meter.

\section{Proses Pirolisis dan Distilasi Asap Cair}

Bahan ditimbang sebanyak $500 \mathrm{~g}$, lalu dimasukan ke dalam tungku pirolisis. Pirolisis dilakukan dengan suhu $250^{\circ}-450^{\circ} \mathrm{C}$ selama \pm 30 menit. Proses pirolisis dilakukan dalam tanur khusus yang tidak memungkinkan adanya keterlibatan oksigen dalam proses pirolisis. Proses pirolisis menghasilkan tiga produk sekaligus yaitu asap cair kasar, ter dan arang yang dapat dijadikan 
bahan baku pembuatan arang aktif (biochar). Asap cair yang dihasilkan memiliki kualitas grade 3 dimana harus dimurnikan menggunakan metode distilasi. Distilasi dilakukan dua kali, yaitu distilasi pertama untuk menghasilkan asap cair grade 2 dan distilasi kedua untuk menghasilkan asap cair grade 1. Distilasi dilakukan dengan alat distilator kaca dengan suhu distilasi $100^{\circ}-110^{\circ} \mathrm{C}$ (Setiawan, 2015).

\section{Parameter Pengujian}

Pengujian yang dilakukan mencakup pengujian kuantitatif dan pengujian kualitatif. Pengujian kuantitatif mencakup volume asap cair kasar menggunakan gelas ukur, volume asap cair distilasi menggunakan gelas ukur, volume ter menggunakan gelas ukur, bobot arang mengguna-kan metode gravimetri, bobot jenis menggunakan metode piknometer, $\mathrm{pH}$ menggunakan indikator universal dan kadar fenol menggunakan metode spektrofotometri. Sedangkan uji kualitatif mencakup warna dan transparansi asap cair.

\section{Pengujian Kadar Total Fenol}

Pengujian menggunakan metode spektrofotometri. Prosedur pengujian pertama yaitu dibuat larutan baku berupa asam galat sesuai dengan penelitian Tahir et al. (2017). Larutan baku yang digunakan terdiri dari enam larutan dengan konsentrasi yang berbeda, yaitu 0 ppm, 1 ppm, 2 ppm, 3 ppm, 4 ppm dan 5 ppm. Masing-masing larutan ditambahkan $1 \mathrm{~mL}$ follin ciocalteu (Merck, Jerman) kemudian dikocok dan dibiarkan selama 48 menit. Ditambahkan $10 \mathrm{~mL} \mathrm{Na}_{2} \mathrm{~S}_{2} \mathrm{O}_{3} 10 \%$ (Merck, Jerman) dan akuades hingga volume $25 \mathrm{~mL}$ dalam labu takar. Kemudian dikocok hingga homogen. Larutan didiamkan selama 2 jam pada suhu ruang. Absorbansi diukur menggunakan spektrofotometer UV-Vis 1800 (Shimadzu, Jepang) pada panjang gelombang $725 \mathrm{~nm}$. Penentuan kadar fenol asap cair dilakukan dengan melakukan preparasi bahan dengan cara sebagai berikut (Noor et al., 2014).

Sepuluh $\mathrm{mL}$ sampel asap cair di-centrifuge menggunakan centrifuge 80-1 (Electrical, Cina) pada 400 rpm selama 10 menit. Dipipet distilat yang sudah di-centrifuge sebanyak $5 \mathrm{~mL}$. Kemudian ditambahkan $1 \mathrm{~mL}$ etanol (Merck, Jerman) dan 0,5 $\mathrm{mL}$ folin ciocalteu. Diamkan selama 5 menit. Tambahkan $1 \mathrm{~mL} \mathrm{Na} \mathrm{S}_{2} \mathrm{O}_{3}$ 10\% kemudian dikocok selama 5 menit. Diamkan dalam ruangan gelap selama 50 menit. Ukur absorbansi sampel menggunakan spektrofotometer UV-Vis 1800 pada panjang gelombang $725 \mathrm{~nm}$ dengan pengenceran 10 kali.
Hasil pengukuran absorbansi dihitung konsentrasinya dengan persamaaan regresi larutan baku yang didapat dengan menggunakan Microsoft Excel. Hasil pengujian berupa data kadar fenol total dengan satuan mg GAE/mL (ekuivalen asam galat).

\section{Pengujian Kadar Asam}

Pengujian kadar asam menggunakan metode titrimetri yaitu dengan menggunakan $\mathrm{NaOH}$ (Merck, Jerman) sebagai bahan pembanding. Konsentrasi larutan $\mathrm{NaOH}$ dibuat $0,1 \mathrm{~N}$. Langkah selanjutnya pipet $1 \mathrm{~mL}$ larutan uji ke dalam erlenmeyer. Kemudian tambahkan $9 \mathrm{~mL}$ akuades dan 2 tetes indikator phenoptalein (Merck, Jerman). Titrasi dengan menggunakan $\mathrm{NaOH}$ sampai berwarna merah muda. Ulangi langkah tersebut hingga didapatkan volume yang konstan. Kemudian hitung kadar keasaman dengan rumus (Wibowo, 2012):

Kadar asam $(\%)=\frac{\text { Volume } \mathrm{NaOH} \times \mathrm{N} \mathrm{NaOH} \times 60}{\text { bobot sampel } \times 1000} \times 100 \%$

\section{HASIL DAN PEMBAHASAN}

\section{Volume Asap Cair Kasar (Crude)}

Kadar air awal bahan sangat mempengaruhi terhadap volume asap cair yang terbentuk. Air akan menguap pada suhu $100^{\circ} \mathrm{C}$ dan terkondensasi sehingga akan menambah volume asap cair yang terbentuk (Nurhayati et al., 2006).

Tabel 1. Kuantitas asap cair kasar yang dihasilkan $(\mathrm{mL})$

\begin{tabular}{lccc}
\hline \multirow{2}{*}{$\begin{array}{c}\text { Bentuk } \\
\text { Bahan }\end{array}$} & $\begin{array}{c}\text { Tanpa } \\
\text { pengeringan }\end{array}$ & $\begin{array}{c}\text { Dengan } \\
\text { pengeringan }\end{array}$ & \\
\cline { 2 - 3 } Rata rata \\
Serbuk & 205,67 & 115,50 & 160,58 \\
Serut & 189,25 & 125,25 & 149,68 \\
Bongkah & 193,62 & 179,12 & 186,37 \\
\hline Rata rata & 191,14 & 139,95 & \\
\hline
\end{tabular}

\section{Volume Asap Cair Distilasi}

Asap cair sudah dapat didistilasi pada suhu $100^{\circ}-110^{\circ} \mathrm{C}$ (Nurhayati et al., 2006). Pada suhu ini kandungan air masih banyak terbawa oleh asap cair sehingga rendemen yang dihasilkan masih cukup tinggi. Pengurangan hasil dari sebelum distilasi dan sesudah distilasi mengacu pada pengendapan zatzat yang tidak menguap seperti ter yang masih terbawa. 
Tabel 2. Kuantitas asap cair distilasi (mL)

\begin{tabular}{cccc}
\hline \multirow{2}{*}{$\begin{array}{c}\text { Bentuk } \\
\text { Bahan }\end{array}$} & $\begin{array}{c}\text { Tanpa } \\
\text { pengeringan }\end{array}$ & $\begin{array}{c}\text { Dengan } \\
\text { pengeringan }\end{array}$ & \\
& Rata rata \\
\hline Serbuk & 181,75 & 79,25 & 130,50 \\
Serut & 174,12 & 112,00 & 150,62 \\
Bongkah & 161,50 & 147,25 & 154,37 \\
\hline Rata rata & 177,50 & 112,83 & \\
\hline
\end{tabular}

\section{Bobot Arang}

Arang yang dihasilkan pada proses pirolisis dipengaruhi oleh kondisi bahan. Bahan dengan perlakuan pengeringan menghasilkan arang atau biochar lebih banyak daripada bahan yang tidak mengalami pengeringan. Bentuk serutan dan serbuk menghasilkan lebih banyak arang secara signifikan setelah mengalami pengeringan yaitu dari $100 \mathrm{~g}$ pada kondisi tanpa pengeringan menjadi $131,25 \mathrm{~g}$ dan $125 \mathrm{~g}$ pada kondisi setelah pengeringan.

Tabel 3. Bobot arang (g)

\begin{tabular}{cccc}
\hline \multirow{2}{*}{ Bentuk } & \multicolumn{2}{c}{ Kondisi bahan } & \\
\cline { 2 - 3 } Bahan & $\begin{array}{c}\text { Tanpa } \\
\text { pengeringan }\end{array}$ & $\begin{array}{c}\text { Dengan } \\
\text { pengeringan }\end{array}$ & \\
\hline Serbuk & 100,00 & 125,00 & 112,50 \\
Serut & 100,00 & 131,25 & 115,62 \\
Bongkah & 100,00 & 121,25 & 110,62 \\
\hline Rata rata & 100,00 & 125,83 & \\
\hline
\end{tabular}

\section{Volume Ter}

Ter merupakan hasil sampingan dari produksi asap cair. Bentuk bahan serutan menghasilkan ter dengan jumlah tertinggi sejumlah $48,375 \mathrm{~mL}$ tanpa pengeringan dan $46,25 \mathrm{~mL}$ setelah pengeringan. Bentuk bongkahan menghasilkan ter dengan jumlah yang tinggi pula pada kondisi tanpa pengeringan yaitu $52 \mathrm{~mL}$ namun pada kondisi kering atau setelah pengeringan hanya $37 \mathrm{~mL}$. Bentuk serbuk menghasilkan ter sebanyak $29,5 \mathrm{~mL}$ pada kondisi tanpa pengeringan dan $39,5 \mathrm{~mL}$ setelah pengeringan.

Tabel 4. Volume ter yang dihasilkan (mL)

\begin{tabular}{cccc}
\hline \multirow{2}{*}{$\begin{array}{c}\text { Bentuk } \\
\text { Bahan }\end{array}$} & $\begin{array}{c}\text { Tanpa } \\
\text { pengeringan }\end{array}$ & $\begin{array}{c}\text { Dengan } \\
\text { pengeringan }\end{array}$ & \\
& Rata rata \\
\hline Serbuk & 29,50 & 39,50 & 34,50 \\
Serut & 48,37 & 46,25 & 47,31 \\
Bongkah & 52,75 & 32,75 & 42,75 \\
\hline Rata rata & 43,54 & 39,50 & \\
\hline
\end{tabular}

\section{Kualitas Asap Cair Grade 1 dan Grade 2}

Asap cair yang dihasilkan berupa asap cair dengan grade 1 dan grade 2 . Grade 2 dihasilkan dari proses distilasi pertama sedangkan grade 1 dihasilkan dari proses distilasi kedua. Kualitas asap cair yang diuji berdasarkan standar asap cair yang dapat diterima oleh Negara Jepang yaitu $\mathrm{pH}$, berat jenis, warna, transparansi, keasaman dan total fenol. Hasil pengujian asap cair grade 2 disajikan dalam Tabel5 dan asap cair grade 1 dalam Tabel 6.

Dalam Tabel 5 dapat dilihat rendemen asap cair distilasi bahan yang tidak dikeringkan lebih tinggi dibandingkan dengan asap cair dari bahan setelah dikeringkan. Kadar air mempengaruhi rendemen di mana semakin tinggi kadar air maka rendemen yang terbentuk akan semakin tinggi. Namun hal ini berkorelasi negatif dengan kualitasnya. Kadar air yang tinggi menurunkan kepekatan bahan aktif asap cair. Hal ini terlihat dalam bobot jenis distilat di mana bobot jenis dapat menunjukan kandungan zat aktif dalam asap cair, semakin tinggi bobot jenis maka semakin tinggi pula kandungan zat aktifnya. Bobot jenis yang dihasilkan masih tetap sesuai dengan kualitas standar Negara Jepang untuk asap cair yaitu > 1,001 g/mL (Alpian et al., 2014; Nurhayati et al., 2006).

Fenol dan keasaman (\%) menjadi 2 komponen utama yang memiliki peran penting dalam pemanfaatan asap cair sebagai anti mikroba. Menurut Noor et al. (2014) semakin tinggi kadar fenol dan kadar asam dari asap cair, maka kemampuan untuk menekan pertumbuhan mikroorganisme dari asap cair tersebut akan semakin tinggi. Menurut Hartati et al. (2013), konidium atau terjadinya lisis pada konidium Colletotrichum capsici disebabkan adanya senyawa kelompok fenol yang terkandung dalam cuka kayu pinus. Hasil pengujian asap cair grade 1 dan grade 2 memiliki kadar fenol yang tidak jauh berbeda pada kisaran 26,66-35,94 mg GAE/mL sampel dan kadar keasaman 16,91-58,9\%.

\section{Kualitas Arang}

Kualitas arang yang diamati adalah kandungan $\mathrm{C}$-Organik dan $\mathrm{pH}$ arang. Arang dengan kandungan C-Organik tinggi dapat memperbaiki sifat kimia tanah, dimana c-organik dibutuhkan tanah dalam pertumbuhan tanaman dan perkembangan mikroflora dan mikrofauna. $\mathrm{pH}$ arang hasil pengujian memberikan hasil yang relatif sama antar perlakuan. 
Tabel 5. Kualitas asap cair distilasi grade 2

\begin{tabular}{|c|c|c|c|c|c|c|c|}
\hline \multirow{3}{*}{ Jenis analisis } & \multicolumn{6}{|c|}{ Nilai } & \multirow{3}{*}{$\begin{array}{c}\text { Standar Jepang } \\
\text { (Nurhayati, } \\
\text { 2006) }\end{array}$} \\
\hline & \multicolumn{3}{|c|}{ Tanpa pengeringan } & \multicolumn{3}{|c|}{ Dengan pengeringan } & \\
\hline & Serbuk & Serutan & Bongkah & Serbuk & Serutan & Bongkah & \\
\hline Rendemen, $\%$ & 36,35 & 37,85 & 32,3 & 15,65 & 22,4 & 29,45 & - \\
\hline $\mathrm{pH}$ & 2 & 2 & 2 & 2 & 2 & 2 & $1,5-3,7$ \\
\hline $\begin{array}{l}\text { Berat jenis, } \\
\mathrm{g} / \mathrm{mL}\end{array}$ & 1,017 & 1,016 & 1,023 & 1,021 & 1,020 & 1,024 & $>1,001$ \\
\hline Warna & $\begin{array}{c}\text { Kuning } \\
\text { kecoklatan }\end{array}$ & $\begin{array}{c}\text { Kuning } \\
\text { kecoklatan }\end{array}$ & $\begin{array}{c}\text { Kuning } \\
\text { kecoklatan }\end{array}$ & $\begin{array}{c}\text { Kuning } \\
\text { kecoklatan }\end{array}$ & $\begin{array}{c}\text { Kuning } \\
\text { kecoklatan }\end{array}$ & $\begin{array}{c}\text { Kuning } \\
\text { kecoklatan }\end{array}$ & $\begin{array}{c}\text { Kuning pucat - } \\
\text { coklat } \\
\text { kemerahan }\end{array}$ \\
\hline Transparansi & $\begin{array}{l}\text { Tidak } \\
\text { keruh }\end{array}$ & $\begin{array}{l}\text { Tidak } \\
\text { keruh }\end{array}$ & $\begin{array}{l}\text { Tidak } \\
\text { keruh }\end{array}$ & $\begin{array}{l}\text { Sedikit } \\
\text { keruh }\end{array}$ & $\begin{array}{l}\text { Sedikit } \\
\text { keruh }\end{array}$ & $\begin{array}{l}\text { Sedikit } \\
\text { keruh }\end{array}$ & $\begin{array}{c}\text { Tidak keruh, } \\
\text { tidak ada yang } \\
\text { terdispersi }\end{array}$ \\
\hline $\begin{array}{l}\text { Kadar total } \\
\text { fenol (mg } \\
\text { GAE/mL } \\
\text { sampel) }\end{array}$ & 35,94 & 35,55 & 29,36 & 35,15 & 33,25 & 29,95 & $x_{2}$ \\
\hline Keasaman (\%) & 18,8 & 21,7 & 46,6 & 46,4 & 48,8 & 58,9 & $1-18$ \\
\hline
\end{tabular}

Tabel 6. Kualitas asap cair distilasi grade 1

\begin{tabular}{|c|c|c|c|c|c|c|c|}
\hline \multirow{3}{*}{ Jenis analisis } & \multicolumn{6}{|c|}{ Nilai } & \multirow{3}{*}{$\begin{array}{c}\text { Standar Jepang } \\
\text { (Nurhayati, 2006) }\end{array}$} \\
\hline & \multicolumn{3}{|c|}{ Tanpa pengeringan } & \multicolumn{3}{|c|}{ Dengan pengeringan } & \\
\hline & Serbuk & Serutan & Bongkah & Serbuk & Serutan & Bongkah & \\
\hline $\mathrm{pH}$ & 2.0 & 2.0 & 2.0 & 2.0 & 2.0 & 2.0 & $1,5-3,7$ \\
\hline $\begin{array}{l}\text { Berat jenis, } \\
\mathrm{g} / \mathrm{mL}\end{array}$ & 1,0149 & 1,0144 & 1,0187 & 1,0181 & 1,0184 & 1,0217 & $>1,001$ \\
\hline Warna & Bening & Bening & Bening & Bening & Bening & Bening & $\begin{array}{c}\text { Kuning pucat - } \\
\text { coklat kemerahan }\end{array}$ \\
\hline Transparansi & $\begin{array}{l}\text { Tidak } \\
\text { keruh }\end{array}$ & $\begin{array}{l}\text { Tidak } \\
\text { keruh }\end{array}$ & $\begin{array}{l}\text { Tidak } \\
\text { keruh }\end{array}$ & $\begin{array}{l}\text { Tidak } \\
\text { keruh }\end{array}$ & $\begin{array}{l}\text { Tidak } \\
\text { keruh }\end{array}$ & $\begin{array}{l}\text { Tidak } \\
\text { keruh }\end{array}$ & Tidak keruh \\
\hline $\begin{array}{l}\text { Kadar total } \\
\text { fenol (mg } \\
\text { GAE/mL } \\
\text { sampel) }\end{array}$ & 34,10 & 34,56 & 27,85 & 26,79 & 26,66 & 27,58 & - \\
\hline Keasaman $(\%)$ & 16,91 & 20,77 & 41,54 & 31,4 & 46,13 & 51,68 & $1-18$ \\
\hline
\end{tabular}

Tabel 7. Hasil analisis arang

\begin{tabular}{lcccccc}
\hline Jenis analisis & \multicolumn{6}{c}{ Nilai } \\
\cline { 2 - 7 } & \multicolumn{3}{c}{ Tanpa pengeringan } & \multicolumn{2}{c}{ dengan pengeringan } \\
\cline { 2 - 7 } & Serbuk & Serutan & Bongkah & Serbuk & Serutan & Bongkah \\
\hline C-Organik (\%) & 5 & 15 & 15 & 5 & 15 & 10 \\
pH & 5 & 6,5 & 6 & 6 & 6 & 5 \\
\hline
\end{tabular}

Korelasi C-Organik berkaitan erat terhadap P-tersedia. Hal ini disebabkan karena semakin tinggi C-Organik pada bahan organik, maka akan terjadi dekomposisi yang menghasilkan asam-asam organik yang menghasilkan anion organik, kemudian akan mengikat ion $\mathrm{Al}, \mathrm{Fe}$ dan $\mathrm{Ca}$ sehingga membentuk senyawa kompleks yang mengakibatkan $\mathrm{P}$ menjadi tersedia di dalam larutan tanah (Wilson et al., 2015). Nilai pH pada bahan arang sangat tergantung pada temperatur pyrolysis dan umur bahan arang yang digunakan. Nilai $\mathrm{pH}$ arang ada pada kisaran pH 11 apabila arang masih segar (belum terlapuk) dan suhu pyrolysis lebih dari $450^{\circ}-500^{\circ} \mathrm{C}$. Apabila arang sudah mengalami 
pelapukan selama dan sesudah proses pirolisi serta bereaksi dengan uap maka nilai $\mathrm{pH}$ arang akan ada di kisaran pH 5-8 (Chan dan Xu, 2009).

\section{KESIMPULAN}

Asap cair yang dihasilkan pada bahan kayu tanpa pengeringan menghasilkan asap cair yang lebih banyak baik yang kasar maupun yang telah didistilasi. Volume ter yang terbentuk tidak dipengaruhi oleh kadar air dan bentuk bahan, sedangkan arang dihasilkan lebih banyak dari bahan yang telah dikeringkan.

Kualitas asap cair distilasi yang diuji menyesuaikan dengan mutu asap cair jepang. Asap cair yang dihasilkan dari bahan yang tidak dikeringkan dan yang telah dikeringkan memiliki karakteristik yang hampir sama, hanya bobot jenis yang berbeda dimana bobot jenis asap cair dari bahan yang dikeringkan lebih tinggi daripada yang tidak dikeringkan.

\section{UCAPAN TERIMAKASIH}

Terimakasih penulis ucapkan kepada Kementerian Riset, Teknologi dan Perguruan Tinggi yang mendanai penuh kegiatan penelitian penulis melalui skema program kreativitas mahasiswa (PKM).

\section{DAFTAR PUSTAKA}

Alpian, T.A. Prayitno, J.P.G. Sutapa, dan Budiadi. 2014. Kualitas asap cair batang gelam (Melaleuca sp.). Jurnal Penelitian Hasil Hutan 32: 83-92. DOI: 10.20886/jphh.2014.32.2.83-92.

Chan, K.Y. and Z. Xu. 2009. Biochar: Nutrient Properties and Their Enhancement. Lehman, J. and S. Joseph (Eds.) Biochar for Environmental Management: Science and Technology. UK: Earthscan p. 67-84.

Hartati, S., R. Meliansyah, dan L.T. Puspasari. 2013. Potensi cuka kayu pinus dalam pengendalian penyakit antraknosa pada cabai merah. Jurnal Fitopatologi Indonesia 9: 173178. DOI: 10.14692/jfi.9.6.173.
Noor, E., C. Luditama, dan G. Pari. 2014. Isolasi dan pemurnian asap cair berbahan dasar tempurung dan sabut kelapa secara pirolisis dan distilasi. In: Prosiding Konferensi Nasional Kelapa VIII, hal. 93-102.

Nurhayati, T., R.A. Pasaribu, dan D. Mulyadi. 2006. Produksi dan pemanfaatan arang dan cuka kayu dari serbuk gergaji kayu campuran. Jurnal Penelitian Hasil Hutan 24: 395-411. DOI: 10.20886/jphh.2006.24.5.395-411.

Purwanto, D. 2011. Pembuatan balok dan papan dari limbah industri kayu. Jurnal Riset Industri 5: 13-20.

Rahmat, B., D. Pangesti, D. Natawijaya, and D. Sufyadi. 2014. Generation of wood-waste vinegar and its effectiveness as a plant growth regulator and pest insect repellent. BioResources 9: 6350-6360.

Setiawan, W. 2015. Pengaruh Asap Cair Tempurung Kelapa Terhadap Patogen Busuk Lunak (Rhizopus stolonifer) Pada Buah Stroberi (Fragaria $\times$ ananassa). Skripsi. Fakultas Pertanian. Universitas Siliwangi.

Tahir, M., A. Muflihunna, dan Syafrianti. 2017. Penentuan kadar fenolik total ekstrak etanol daun Nilam (Pogostemon cablin Benth.) dengan metode spektrofotometri UV-Vis. Jurnal Fitofarmaka Indonesia 4: 215-218. DOI: 10.33096/jffi.v4i1.231.

Tiilikkala, K., L. Fagernäs, and J. Tiilikkala. 2010. History and use of wood pyrolysis liquids as biocide and plant protection product. The Open Agriculture Journal 4: 111-118. DOI: 10.2174/1874331501004010111.

Wibowo, S. 2012. Karakteristik asap cair tempurung nyamplung. Jurnal Penelitian Hasil Hutan 30: 217-226. DOI: 10.20886/jphh.2012.30.3.218-227

Wilson, Supriadi, dan H. Guchi. 2015. Evaluasi sifat kimia tanah pada lahan kopi di Kabupaten Mandailing Natal. Jurnal Online Agroekoteknologi 3: 642-648.

Yokoyama, S. and Y. Matsumura. 2008. The Asian Biomass Handbook: A Guide for Biomass Production and Utilization Support. 1 ed. Tokyo: Ministry of Agriculture, Forestry and Fisheries. 